\title{
Distribution of Lesions in Red and Fallow Deer Naturally Infected with Mycobacterium bovis
}

\author{
M. P. Martín-Hernando*, M. J. Torres ${ }^{\dagger}$, J. Aznar ${ }^{\dagger \neq}$, J. J. Negro ${ }^{x}$, \\ A. Gandía ${ }^{\ddagger}$ and C. Gortázar* \\ * IREC National Wildlife Research Institute (CSIC-UCLM-JCCM), Ciudad Real, ${ }^{\dagger}$ Departamento de Microbiología, \\ Universidad de Sevilla, ${ }^{*}$ Instituto de Biomedicina de Sevilla, Hospital Universitario Virgen del Rocío/CSIC/Universidad de \\ Sevilla and ${ }^{\mathrm{x}}$ Estación Biológica de Donana, CSIC, Sevilla, Spain
}

\begin{abstract}
Summary
Wild deer have an important role in the epidemiology of bovine tuberculosis (bTB). The aims of this study were (1) to compare the pattern of lesions present in wild red (Cervus elaphus) and fallow (Dama dama) deer that were naturally infected with Mycobacterium bovis, and (2) to use this information to develop a sampling strategy for the isolation of M. bovis from the lymphoid tissues of the head of these animals. Culture of head lymphoid tissues demonstrated that 28 of 95 red deer and 22 of 100 fallow deer sampled were infected with M. bovis. Approximately $30 \%$ of each deer population had no gross lesions. Fallow deer were significantly more likely to have thoracic lesions than red deer. Lesions were observed in the retropharyngeal lymph nodes of $64 \%$ of the culture-positive red deer and $43 \%$ of the culture positive fallow deer. One third of the red deer, but none of the fallow deer, had well-encapsulated abscess lesions. There were no microscopical differences in the lesions in the lymph nodes of the red and fallow deer. Bacteriological culture from both the tonsil and retropharyngeal lymph nodes increased the rate of isolation of $\mathrm{M}$. bovis by $22 \%$ over culture of the retropharyngeal lymph nodes alone in both species. These findings indicate that investigation of wild deer for bTB-compatible lesions should include examination of the medial retropharyngeal, left tracheobronchial, mediastinal, mesenteric and ileocaecal lymph nodes. Sampling for bacteriological culture from head lymphoid tissues should be from the tonsil and the medial retropharyngeal lymph nodes. These protocols may prove useful in bTB surveillance and control in regions where wild deer contribute to the circulation of $\mathrm{M}$. bovis.
\end{abstract}

Keywords: bovine tuberculosis; lymphoid tissue; Mycobacterium bovis; wild deer

\section{Introduction}

Bovine tuberculosis (bTB) caused by Mycobacterium bovis and closely related members of the Mycobacterium tuberculosis complex (MTbC) has been reported worldwide in domestic animals and in wildlife. The white-tailed deer (Odocoileus virginianus) is recognized as a wildlife reservoir of infection; however, the red deer (Cervus elaphus) and domestic deer hybrids are also considered maintenance hosts in some regions (Corner, 2006). In Europe, MTbC infection has been reported in red deer and fallow deer (Dama dama) and less frequently in roe deer (Capreolus capreo-

Correspondence to: C. Gortazar (e-mail: christian.gortazar@uclm.es). lus) and other exotic deer species (Delahay et al., 2007; Partridge et al., 2008; Balseiro et al., 2009). Hence, deer may have an important role in the epidemiology of bTB.

Red deer have almost worldwide distribution as they have been widely introduced for hunting purposes or as farmed animals, and bTB has been diagnosed in this species in all continents except Antarctica. The highest prevalence of infection (above 50\%) occurs in farmed deer (Mackintosh et al., 2004), while in wild populations the prevalence is rarely above 20\% (Vicente et al., 2006; Delahay et al., 2007; Zanella et al., 2008). Lesions in deer are most often described in the lymph nodes (particularly the medial retropharyngeal nodes) 
and in the lungs. In New Zealand, over $50 \%$ of gross lesions in both farmed and wild red deer occur in the lymph nodes of the head, especially the medial retropharyngeal node. Lesions also occur in the oropharyngeal tonsils, the mediastinal, bronchial and mesenteric lymph nodes and the lung (Mackintosh et al., 2004). One study of Canadian farmed elk and red deer with $\mathrm{M}$. bovis infection detected more lung lesions than lesions in the mesenteric lymph nodes (Rohonczy et al., 1996). However, a report of seven infected wild red deer from Austria described lesions in the abdominal organs of four animals (Glawischnig et al., 2003) and a recent survey in France also revealed that lesions were most often found in the mesenteric lymph nodes (Zanella et al., 2008). These lesions were often abscess-like, poorly encapsulated granulomas, which frequently contained numerous acid fast organisms (Mackintosh et al., 2004; Johnson et al., 2008). The lesions in elk and red deer usually have scattered foci of peripheral mineralization rather than central mineralization and contain more neutrophils and fewer giant cells than lesions occurring in cattle (Rhyan and Saari, 1995). The tonsil is probably a common primary site of infection (Lugton et al., 1998) and is considered to be a major site of persistence of $\mathrm{M}$. bovis in both naturally and experimentally infected red deer (Lugton et al., 1998; Griffin et al., 2006). However, tonsillar lesions may only be detected in $50 \%$ of culture-positive samples and up to $28 \%$ of deer with no gross lesions may still be culture-positive (Lugton et al., 1998; GavierWiden et al., 2009).

While individual cases or epidemiological surveys have also been reported from fallow deer (Wilson and Harrington, 1976; Robinson et al., 1989; Wahlstrom et al., 1998), far less is known about bTB lesions and lesion distribution in this species. Rhyan and Saari (1995) observed that lesions in fallow deer contained more giant cells, but were otherwise indistinguishable from those occurring in elk or red deer. A recent histopathological study reported no significant difference between the lesions occurring in infected red or fallow deer (Johnson et al., 2008).

Since bTB lesions in deer are most often described in the medial retropharyngeal lymph nodes, these are often targeted in active surveillance schemes (VerCauteren et al., 2008). The highest prevalence of $\mathrm{M}$. bovis infection ever reported in a free living deer population occurred in Dorrana National Park (DNP), in southern Spain (Gortazar et al., 2008). The aims of the present study were therefore to use this population to (1) characterize and compare the distribution of lesions in red and fallow deer, and (2) to use this information to develop a sampling pro- tocol for the isolation of $\mathrm{M}$. bovis from the lymphoid tissues of the head of these animals.

\section{Materials and Methods}

\section{Animals}

From April 2006 to April 2007, 95 wild red deer and 100 wild fallow deer were sampled within Donana National Park (DNP; $37^{\circ} 0^{\circ} \mathrm{N}, 6^{\circ} 30^{\circ} \mathrm{W}$, south-western Spain). Animals were shot by DNP officers with a permit from the Park and under the authority of Consejeria de Medio Ambiente, Junta de Andalucia. A necropsy examination was performed in the field, including detailed determination of morphometry, body mass and sex. Based on tooth eruption patterns, animals less than 12 months old were classified as juveniles, those between 12 and 24 months as yearlings and those more than 2 years old as adults (Saenz de Buruaga et al., 1991).

\section{Microbiology}

Culture was performed separately on lymph node and tonsillar tissue. Sample preparation and culture methodology were as described by Gortazar et al. (2008). Briefly, the specimens (1e $4 \mathrm{~g}$ of tissue) were decontaminated with $\mathrm{N}$-acetyl-L-cysteine and $\mathrm{NaOH}$, concentrated by centrifugation and inoculated in solid Lowenstein-Jenssen medium with pyruvate. Identification to species level was performed with the GenoType ${ }^{\circledR}$ MTBC system (Hain Lifescience GmbH, Nehren, Germany).

\section{Gross Pathology}

The necropsy examination included detailed macroscopic inspection of lymph nodes and abdominal and thoracic viscera. This examination routinely included the parotid, lateral and medial retropharyngeal and submandibular lymph nodes of the head. The tracheobronchial and mediastinal lymph nodes and lungs were examined within the thorax. Within the abdomen, the hepatic, mesenteric and ileocaecal lymph nodes, ileocaecal valve, liver, kidneys and spleen were examined. Any gross lesions in other locations were also recorded. Lymph nodes were dissected and sectioned serially. Tonsils were routinely sampled for culture, but were not sectioned. Any gross tonsillar lesions were recorded.

\section{Histopathology}

Tissue samples from the lymph nodes listed above and the diaphragmatic lung lobes, kidneys, adrenals, liver, spleen, ileocaecal valve and any other lesions were fixed in $10 \%$ neutral buffered formalin, 
processed routinely and embedded in paraffin wax. Sections $(4 \mathrm{~mm})$ were stained with haematoxylin and eosin (HE) and by the ZiehleNeelsen (ZN) method. Gram and periodic acid-Schiff (PAS) stains were performed in order to identify any non-mycobacterial granulomas (Martın-Hernando et al., 2007).

Granulomas were classified according to their size (A $<1 \mathrm{~cm}$ and $\mathrm{B}>1 \mathrm{~cm}$ ) and composition. A type 1 or early granuloma consisted of mixed inflammatory cells, sometimes with a necrotic core. A type 2 granuloma had mild necrosis and calcification, with minor calcium deposition in the necrotic core. A type 3 granuloma had marked necrosis and calcification, with an area of calcification similar to, or more extensive than, the area of necrosis. This classification scheme encompasses the consecutive stages of mycobacterial infection and is of epidemiological relevance (Bollo et al., 2000; Gavier-Widen et al., 2001; Wangoo et al., 2005; Martın-Hernando et al., 2007). The number and characteristics of satellite granulomas were also recorded. Satellite granulomas develop by expansion of bacilli from the initial focus (Dungworth, 1993).

The degree of encapsulation of the lesions was scored as 0 (no capsule), 1 (sparse connective tissue), 2 (dense connective tissue) or 3 (a thick capsule of connective tissue). Multinucleated giant cells were quantified in $10 \times 100$ fields in each granuloma.

Finally, acid-fast bacilli were quantified in the ZNstained slides by counting organisms in 200 fields per section (at $\times 1,000$ magnification). The final count for a given individual was expressed as the mean number of mycobacteria found per tissue section (MartınHernando et al., 2007).

\section{Statistical Analysis}

The kappa statistic was used to measure the agreement between different techniques. Homogeneity was tested by chi square analysis or, where appropriate, Fisher's exact test. Numerical data of indepen- dent groups were compared with the Mann Whitney U test.

\section{Results}

Lesion Distribution

Culture of the medial retropharyngeal lymph nodes and tonsil confirmed that 28 red deer and 22 fallow deer were infected with $M$. bovis. In both the red and the fallow deer, lesions compatible with bTB were more often present in the culture-confirmed animals (82.1\%, 23/28; and 68.2\%, 15/22, respectively), than in culture-negative deer $(29.8 \%, 20 / 67$; and $17.9 \%$, 14/78, respectively; Table 1). Only three out of $20(15 \%)$ culture negative red deer and no culture-negative fallow deer had lesions compatible with bTB, and these were present in the retropharyngeal lymph nodes. The following results refer only to culture-positive deer.

Table 2 shows the distribution of bTB-compatible lesions in $\mathrm{M}$. bovis-positive red and fallow deer. The proportion of individuals with no gross lesions compatible with bTB (NGL) was close to $30 \%$ for both red and fallow deer. However, microscopical lesions were present in three out of eight NGL red deer, but in none of the seven NGL fallow deer. In both species, gross lesions were almost always larger than $1 \mathrm{~cm}$ (B lesions). In $\mathrm{M}$. bovis-infected red deer, gross lesions were most frequently observed in the retropharyngeal lymph nodes followed by the abdominal tissues (mainly the ileocaecal and mesenteric lymph nodes), while in fallow deer the lesion frequency was highest in the thoracic region (mainly the left tracheobronchial and mediastinal lymph nodes). The proportion of thoracic lesions was significantly higher in fallow deer than in red deer. The percentage of infected animals with generalized bTB, defined as lesions occurring in more than one region, did not differ between red deer $(46.4 \%, 13 / 28)$ and fallow deer $(45.4 \%, 10 /$ 22; $c^{2} 1 / 40.3,1$ degree of freedom, $\left.P>0.05\right)$. In red deer, thoracic lesions were found only in animals with lesions in both the head and the abdominal tissues. In fallow deer, abdominal lesions were found

Table 1

Comparison of culture and lesion positivity in red and fallow deer

\begin{tabular}{|c|c|c|c|c|c|c|c|}
\hline & & \multicolumn{4}{|c|}{ Lesion present } & \multirow[t]{2}{*}{ Lesion absent } & \multirow[t]{2}{*}{ Total } \\
\hline & & Gross only & Microscopical only & $\begin{array}{l}\text { Both gross } \\
\text { and microscopical }\end{array}$ & Total & & \\
\hline \multirow[t]{2}{*}{ Red deer } & Culture + & 3 & 3 & 17 & 23 & 5 & 28 \\
\hline & Culture - & 12 & 7 & 1 & 20 & 47 & 67 \\
\hline \multirow[t]{2}{*}{ Fallow deer } & Culture + & 1 & 0 & 14 & 15 & 7 & 22 \\
\hline & Culture - & 2 & 4 & 8 & 14 & 64 & 78 \\
\hline
\end{tabular}


Table 2

Proportion of M. bovis-infected red deer and fallow deer with or without gross lesions

\begin{tabular}{|c|c|c|c|c|c|}
\hline \multirow{2}{*}{$\begin{array}{l}\text { Lesions present in } \\
\text { NGL }\end{array}$} & \multicolumn{2}{|c|}{ Red deer } & \multicolumn{2}{|c|}{ Fallow deer } & \multirow{2}{*}{$\frac{c^{2}}{0.62 *}$} \\
\hline & $28.6 \%$ & $(8 / 28)$ & $31.8 \%$ & $(7 / 22)$ & \\
\hline Head & $64.3 \%$ & $(18 / 28)$ & $44.4 \%$ & $(10 / 22)$ & $1.77^{*}$ \\
\hline Thorax & $21.4 \%$ & $(6 / 28)$ & $50 \%$ & $(11 / 22)$ & $4.48, \mathrm{P}<0.05$ \\
\hline Abdomen & $53.6 \%$ & $(15 / 28)$ & $40.9 \%$ & $(9 / 22)$ & $0.79 *$ \\
\hline
\end{tabular}

NGL, no gross lesions.

*Not significant.

Table 3

Distribution of gross lesions in $\mathrm{M}$. bovis-infected red and fallow deer

\begin{tabular}{|c|c|c|c|c|c|}
\hline \multirow[t]{2}{*}{ Group } & \multirow[t]{2}{*}{ Lesion distribution } & \multicolumn{2}{|c|}{ Red deer } & \multicolumn{2}{|c|}{ Fallow deer } \\
\hline & & Lymph node lesion & Visceral lesion & Lymph node lesion & Visceral lesion \\
\hline 1 & Head only & 5 & 0 & 3 & 0 \\
\hline 2 & Head and thorax & 0 & 0 & 2 & 2 (lung) \\
\hline 3 & Thorax only & 0 & 0 & 1 & 1 (lung) \\
\hline 4 & Head and abdomen & 7 & $6(\mathrm{ICV})$ & 0 & 0 \\
\hline 6 & Head, thorax and abdomen & 6 & $6^{*}$ & 6 & $5^{\dagger}$ \\
\hline 7 & Thorax and abdomen & 0 & 0 & 3 & $3^{\ddagger}$ \\
\hline Total & & 20 & 12 & 15 & 11 \\
\hline
\end{tabular}

*Lesions in ileocaecal valve (ICV; 6), lung (3), liver (3) and omentum (2).

${ }^{\dagger}$ Lesions in lung (5), ICV (4), spleen (2) and liver (1).

${ }^{\ddagger}$ Lesions in lung (3), ICV, omentum and liver (2) and spleen (1).

only in animals with lesions in the head and thorax (Table 3).

With the exception of one red and one fallow deer, all animals with generalized lymph node lesions also had visceral lesions. Culture-positive and lesion-positive animals comprised $60 \%$ of the red deer and $73 \%$ of the fallow deer. The most commonly affected vis- cera included the ileocaecal valve $(60 \%$ in red deer, $40 \%$ in fallow deer) and the lung $(15 \%$ in red deer and $73 \%$ in fallow deer). Ten of 13 red deer and eight of 10 fallow deer with generalized lesions were adults, but the sample was biased towards animals of this age group (74 of 95 red deer and 83 of 100 fallow deer). There was no sample bias regarding the gender of

Table 4

M. bovis isolation and bTB-compatible lesions observed in the retropharyngeal lymph nodes and tonsils of red and fallow deer

\begin{tabular}{|c|c|c|c|c|c|c|c|}
\hline & \multirow[t]{2}{*}{ M. bovis isolated } & \multicolumn{2}{|c|}{$\begin{array}{l}\text { Retropharyngeal lymph } \\
\text { node lesions }\end{array}$} & \multirow[t]{2}{*}{$\begin{array}{l}\text { Retropharyngeal lymph } \\
\text { node not analyzed }\end{array}$} & \multicolumn{2}{|c|}{ Tonsil lesions } & \multirow[t]{2}{*}{ Tonsil not analyzed } \\
\hline & & Present & Absent & & Present & Absent & \\
\hline \multirow[t]{4}{*}{ Red deer } & $\begin{array}{c}\text { Retropharyngeal lymph } \\
\text { node (10) }\end{array}$ & 6 & 3 & 1 & 0 & 10 & 0 \\
\hline & Tonsil (5) & 3 & 2 & 0 & 0 & 5 & 0 \\
\hline & Both (13) & 9 & 4 & 0 & 3 & 10 & 0 \\
\hline & Total (28) & 18 & 9 & 1 & 3 & 25 & 0 \\
\hline \multirow[t]{4}{*}{ Fallow deer } & $\begin{array}{c}\text { Retropharyngeal lymph } \\
\text { node (13) }\end{array}$ & 8 & 5 & 0 & 2 & 9 & 2 \\
\hline & Tonsil (4) & 1 & 1 & 1 & 0 & 4 & 0 \\
\hline & Both (4) & 5 & 0 & 0 & 0 & 3 & 1 \\
\hline & Total (21) & 14 & 6 & 1 & 2 & 16 & 3 \\
\hline
\end{tabular}


the animals (red deer: 44 females and 51 males; fallow deer: 46 females and 54 males). Generalized lesions were found in seven red deer males and six females, and in eight fallow deer males and two females ( $c^{2} 1 / 43.0,1$ degree of freedom, $\mathrm{P}>0.05$ ).

Lesions were observed in the medial retropharyngeal lymph nodes of $64 \%$ of the culture-positive red deer (18/28). In fallow deer, medial retropharyngeal lymph node lesions were observed in $44 \%$ of the culture-positive animals (10/22). In contrast, tonsillar lesions compatible with bTB were observed in only five animals (three red and two fallow deer). These were always associated with medial retropharyngeal lymph node lesions (Table 4).

\section{Histopathology}

Microscopical examination permitted detection of lesions compatible with bTB in three of $23 \mathrm{M}$. bovis-infected red deer without gross lesions (Table 1). Tuberculous granulomas in both deer species had large necrotic centres with calcification. Granulomas were surrounded by a layer of mononuclear cells and macrophages in different stages of development, including Langhans type cells. Outside this layer, a connective tissue capsule was present. These granulomas were frequently large and eventually affected the entire organ. Macrophages were present within the capsule and as small groups in the parenchyma of the affected organ (satellite granulomas). Acid-fast organisms (AFOs) were generally present in low number and were mostly observed within epithelioid and giant cells.

The histopathological features of the tuberculous lesions in $18 \mathrm{M}$. bovis-infected red deer were compared with those in $14 \mathrm{M}$. bovis-infected fallow deer. The level of calcification was similar in both species. The highest calcification levels were observed in red deer with generalized lesions.

The number of giant cells per granuloma was only slightly higher in red deer than in fallow deer (2.64 \pm 0.56 versus $1.90 \pm 0.66$, respectively; $U$ test, $\mathrm{P}>0.05$ ), although the number of Langhans giant cells was similar in both species (0.46 in red deer and 0.43 in fallow deer). In fallow deer, small groups of epithelioid and giant cells separated by connective tissue surrounded the necrotic centre (Fig. 1). This change was not seen in red deer, where giant cells and epithelioid cells were homogeneously distributed around the necrotic core (Fig. 2).

The capsule of the granulomas was more obvious in the lesions of red deer than in those of fallow deer. This was mainly because one-third of the red deer (six of 18) had abscesses with thick capsules, while none of the fallow deer had such lesions (0 of 12; Fish-

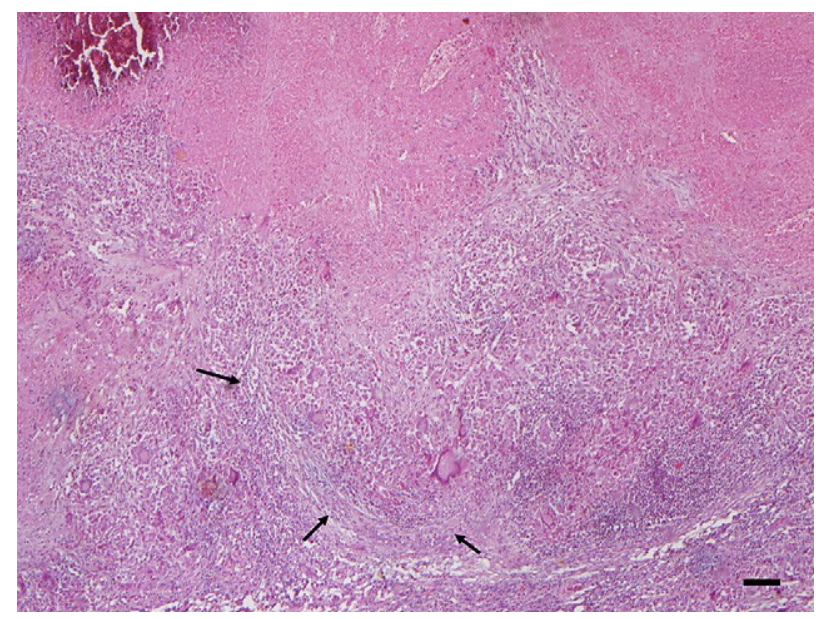

Fig. 1. Tuberculous granuloma in the lymph node of a fallow deer. Small groups of epithelioid and giant cells separated by sparse connective tissue (arrows) surround the necrotic centre of the lesion (top). HE. Bar, $50 \mathrm{~mm}$.

er's test, $\mathrm{P}<0.05)$. The lesions in five of 14 fallow deer had no capsule at all. On a scale of $0 \mathbf{e} 3$, the mean degree of capsule development was $1.44 \pm 0.26$ in red deer and $0.79 \pm 0.30$ in fallow deer, but this difference was not statistically significant (U test, $\mathrm{P}>0.05$ ). Red deer with localized lesions had less encapsulated granulomas than those animals with generalized lesions, but this difference was not evident in fallow deer.

Satellite granulomas were less often found in red deer (three of 12, 25\%) than in fallow deer (nine of 13, 69.23\%; P > 0.05). Moreover, the satellite granulomas were less developed in red deer than in fallow deer (mean score 0 in red deer versus $0.33 \pm 0.18$ in fallow deer; $\mathrm{U}$ test, $\mathrm{P}>0.05$ ).

AFOs were as often observed in tuberculous granulomas of red deer $(43.7 \%)$ as in those of fallow deer (42.9\%). The number of AFOs was low except for

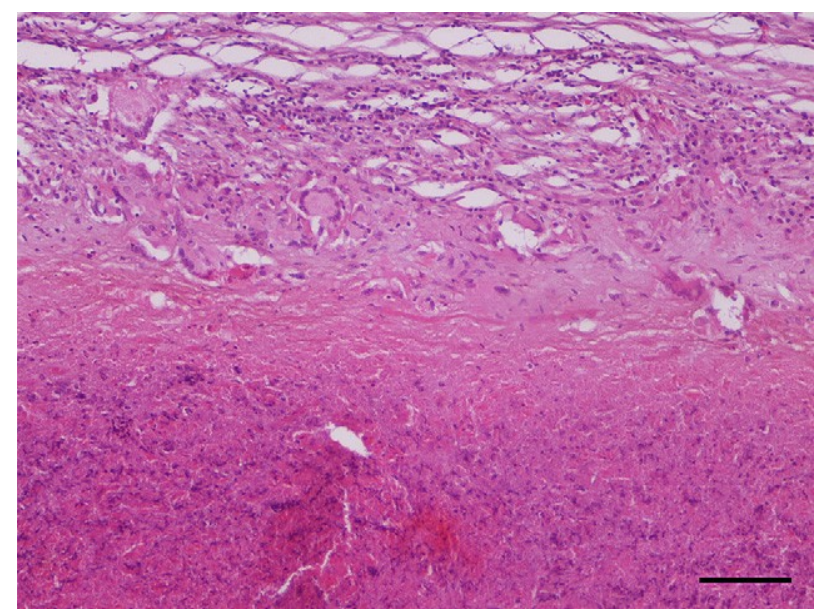

Fig. 2. Tuberculous granuloma in the lymph node of a red deer. Giant cells and epithelioid cells are homogeneously distributed around the necrotic core (top). HE. Bar, $50 \mathrm{~mm}$. 
in 2 red deer (an adult stag and a yearling hind) where the lesions contained moderate numbers of organisms.

\section{Sampling Strategy}

In red deer, M. bovis was isolated more frequently from the retropharyngeal lymph nodes (23 cases) than from the tonsils (18 cases). In 5 animals the agent was detected exclusively in the tonsil. In fallow deer, $\mathrm{M}$. bovis was also isolated more often from the retropharyngeal lymph nodes (18 cases) than from the tonsils (8 cases). In 4 animals the agent was detected exclusively in the tonsil. Thus, the routine inclusion of culture from the tonsil would improve the likelihood of isolating $\mathrm{M}$. bovis by $22 \%$ in both red deer and fallow deer, as compared with culture from the retropharyngeal lymph nodes alone.

The kappa agreement coefficient was calculated twice, firstly in animals with bTB-compatible lesions in the head lymph nodes or tonsils, and secondly in all animals, even if no head lesions were observed. In red deer with head lesions, the kappa agreement between microbiology and pathology was 0.74 . In fallow deer with head lesions, the kappa value was 0.57 . Considering all deer regardless of the presence of head lesions, the kappa agreement between culture and pathology was 0.45 for both red and fallow deer.

\section{Discussion}

The results of the present study have shown differences in the distribution and microscopical characteristics of lesions in red and fallow deer naturally infected with $\mathrm{M}$. bovis. These data suggest that routine sampling for diagnostic purposes should include culture from the tonsil in addition to the retropharyngeal lymph node. There also appears to be broad agreement between pathology and culture as diagnostic procedures for $M$. bovis infection in these animal species.

In the geographical area of the present study, a slightly lower prevalence of $\mathrm{M}$. bovis infection was detected in fallow deer (22\%) as compared with red deer (29.5\%), despite the fact that fallow deer are more gregarious and graze (instead of browsing) proportionally more often than red deer. These are both factors that are known to increase the risk of infection (Gortazar et al., 2008). Lesions in the lung and the thoracic lymph nodes were more often observed in fallow deer, suggesting that airborne transmission may be of greater importance in this species than in red deer. The finding that M.bovis-infected red deer more often had lesions in the abdominal than in the thoracic region is in contrast with observations in some earlier studies of wild and farmed deer (de Lisle and Havill, 1985; Rohonczy et al., 1996); but is in agreement with studies of wild red deer in Europe (Clifton-Hadley and Wilesmith, 1991; Glawischnig et al., 2003; Zanella et al., 2008).

In the present study, there were few differences between the 2 deer species with respect to microscopical features such as calcification, the presence of satellite granulomas and giant cells and the number of AFOs. The lesions of fallow deer had slightly less calcification and encapsulation than those of red deer. These observations are consistent with those of Robinson et al. (1989) but not with those of Rhyan and Saari (1995). Abscesses with a thick wall of connective tissue were often present in red deer but never in fallow deer. The abscess lesions previously recorded in deer generally had a thin capsule (Mackintosh et al., 2004; Johnson et al., 2008). According to the literature, a lesser degree of encapsulation suggests a lower ability to cope with the infection (CliftonHadley and Wilesmith, 1991; Dungworth, 1993). The data related to the frequency of satellite granulomas and on the number and distribution of giant cells, are also consistent with a reduced ability of fallow deer to contain the infection. In contrast, other studies have found that giant cells were more frequent in the lesions of fallow deer than those of red deer (Rhyan and Saari, 1995).

The lesions of the deer in the present study were characterized by the presence of low numbers of AFOs. The number of AFOs can vary considerably in deer (Clifton-Hadley and Wilesmith, 1991; Rhyan and Saari, 1995), but is usually higher in recent infections and in severe cases associated with mortality (Wilson and Harrington, 1976; Dodd, 1984; Johnson et al., 2008), when compared with chronic infections (Stuart et al., 1988; Robinson et al., 1989). Hence, the deer sampled in this study may generally have had chronic infection.

High percentages of deer with no gross mycobacterial lesions have also been reported in farm outbreaks (de Lisle and Havill, 1985). In terms of lesion distribution patterns, generalized lesions are less often reported in recent infections of both wild and farmed deer (de Lisle and Havill, 1985). In contrast, generalized lesions are often reported in chronic infections and in farms with poor bTB control (Stuart et al., 1988; Mackintosh et al., 2004). This was also probably the case in the geographical area of the present study. However, a high rate of generalized disease may also be due to a higher susceptibility to systemic spread of infection (Dungworth, 1993; Mackintosh et al., 2004) and indicate a reduced genetic resistance (Acevedo-Whitehouse et al., 2005; Naranjo et al., 2008). The presence of thicker capsules in red deer, especially in those animals with 
generalized disease, may be interpreted to mean a higher resistance to the infection in that species.

As expected given previous reports on red deer (de Lisle and Havill, 1985; Mackintosh et al., 2004), deer from the present study often displayed bTB-compatible lesions in the retropharyngeal lymph nodes. This observation suggests that large scale studies relying only on inspection of the lymphoid tissue of the head will detect a significant proportion of bTB infected red (64\%) and fallow deer (44\%). Moreover, there was good agreement between the observation of bTB-compatible lesions in the lymphoid tissues of the head and isolation of $\mathrm{M}$. bovis from these tissues. Kappa agreement between positive culture and the presence of head lesions was 0.74 in red deer, which is close to the 0.8 reported in farmed animals (Rohonczy et al., 1996). However, these kappa values are well above the figure of 0.2 reported in a recent study of wild red deer (Zanella et al., 2008). These differences probably reflect differences in the pathology protocols in the different studies.

It is optimal to inspect the abdominal organs (in particular the mesenteric lymph nodes and ileocaecal valve) in red deer and the lung and associated lymph nodes in fallow deer. This contrasts with the situation in European wild boar infected with M. bovis, where studies have shown that inspection of the mandibular lymph nodes alone would permit detection of $>90 \%$ of infected individuals with bTB-compatible lesions (Martın-Hernando et al., 2007).

Thirty percent of red deer and $18 \%$ of fallow deer that were culture negative in the present study had lesions compatible with bTB. These individuals may include both false negatives (infected but culture negative) and deer infected by other organisms that produce similar lesions. For example, mesenteric lymph node and ileocaecal valve lesions caused by M. avium paratuberculosis are difficult to distinguish from those of bTB (Rohonczy et al., 1996; Mackintosh et al., 2004). However, these figures contrast with the $30 \%$ of both deer species that were culture positive but without gross lesions. Moreover, bTB-compatible lesions in the retropharyngeal lymph nodes were only observed in $15 \%$ of the red deer and none of the fallow deer. Thus, lesion-based surveillance would produce figures that do not significantly differ from the “true" prevalence (see Vicente et al., 2006 for an example of lesion-based surveillance).

As shown in the present study, including culture of the tonsil in the diagnostic protocol would increase the probability of isolating $\mathrm{M}$. bovis by $22 \%$, as compared with culture from the retropharyngeal lymph node alone. It is likely that this figure may have been even greater had culture from the thoracic and mesenteric lymph nodes also been included (de Lisle and Havill, 1985; Crawshaw et al., 2008). However, in animals that are shot, thoracic and abdominal organs are often damaged and contaminated. This may require more intense decontamination of the tissue samples prior to culture and cause a loss of sensitivity, particularly in large scale studies under field conditions (Vicente et al., 2006).

In conclusion, inspection of wild deer for the presence of lesions compatible with bTB should routinely include multiple sectioning of both medial retropharyngeal, and the left tracheobronchial, mediastinal, mesenteric and ileocaecal lymph nodes. Culture should be performed from the tonsil in addition to the medial retropharyngeal lymph nodes. This suggested protocol may prove useful in bTB surveillance and control in regions where wild deer contribute to the spread of M. bovis.

\section{Acknowledgments}

The authors thank M. Reglero, J. A. Gamarra, J. A. Muriel, D. Cobos and colleagues from the Donana National Park for making the sampling possible. This study was funded by Consejerra de Medio Ambiente, Junta de Andalucia. This is a contribution to CICYT e MEC research grant AGL2008-03875 and FEDER, and to EU grant TB-STEP 212414. Studies on diseases shared between domestic animals and wildlife are also supported by grants and contracts from INIA, Principado de Asturias, Castilla e La Mancha (GC-006), Ministerio de Medio Ambiente y Medio Rural y Marino (OAPN and SDGSPP), and Grupo Santander e Fundacion Marcelino Botin. MPM-H acknowledges a post doctoral contract from the Instituto de Salud Carlos III.

\section{References}

Acevedo-Whitehouse K, Vicente J, Gortazar C, Hofle U, Fernandez-De-Mera IG et al. (2005) Genetic resistance to bovine tuberculosis in the Iberian wild boar. Molecular Ecology, 14, 3209e3217.

Balseiro A, Oleaga A, Orusa R, Robetto S, Zoppi S et al. (2009) Tuberculosis in roe deer from Spain and Italy. Veterinary Record, 164, 468e470.

Bollo E, Ferroglio E, Dini V, Mignone W, Biolatti B et al. (2000) Detection of Mycobacterium tuberculosis complex in lymph nodes of wild boar (Sus scrofa) by a target-amplified test system. Journal of Veterinary Medicine Series B, 47, 337e342.

Clifton-Hadley RS, Wilesmith JW (1991) Tuberculosis in deer: a review. Veterinary Record, 129, 5e12.

Corner LAL (2006) The role of wild animal populations in the epidemiology of tuberculosis in domestic animals: how to assess the risk. Veterinary Microbiology, 112, $303 \mathbf{e} 312$. 
Crawshaw TR, Griffiths IB, Clifton-Hadley RS (2008) Comparison of a standard and a detailed post mortem protocol for detecting Mycobacterium bovis in badgers. Veterinary Record, 163, $473 \mathbf{e} 477$.

Delahay RJ, Smith GC, Barlow AM, Walker N, Harris A et al. (2007) Bovine tuberculosis infection in wild mammals in the South-West region of England: a survey of prevalence and a semi-quantitative assessment of the relative risks to cattle. Veterinary Journal, 173, 287 e301.

Dodd K (1984) Tuberculosis in free-living deer. Veterinary Record, 115, 592e593.

Dungworth DL (1993) The respiratory system. In: Pathology of Domestic Animals, 4th Edit., vol. 2, KVF Jubb, PC Kennedy and N Palmer, Eds, Academic Press, San Diego, pp. 539e699.

Gavier-Widen D, Chambers MA, Palmer N, Newell DG, Hewinson RG (2001) Pathology of natural Mycobacterium bovis infection in European badgers (Meles meles) and its relationship with bacterial excretion. Veterinary Record, 148, 299 e307.

Gavier-Widen D, Cooke MM, Gallagher J, Chambers MA, Gortazar C (2009) A review of infection of wildlife hosts with Mycobacterium bovis and the diagnostic difficulties of the 'no visible lesion' presentation. New Zealand Veterinary Journal, 57, $122 \mathbf{e} 131$.

Glawischnig W, Allerberger F, Messner C, Schonbauer M, Prodinger WM (2003) Tuberculosis in free-living red deer (Cervus elaphus hippelaphus) in the northern Alps. Wiener Tierärztliche Monatsschrift, 90, 38e44.

Gortazar C, Torres MJ, Vicente J, Acevedo P, Reglero M et al. (2008) Bovine tuberculosis in Dorrana Biosphere Reserve: the role of wild ungulates as disease reservoirs in the last Iberian Lynx strongholds. PLoS ONE, 3, e2776. doi:10.1371/journal.pone.0002776.

Griffin JF, Rodgers CR, Liggett S, Mackintosh CG (2006) Tuberculosis in ruminants: characteristics of intra-tonsilar Mycobacterium bovis infection models in cattle and deer. Tuberculosis, 86, 404e418.

Johnson LK, Liebana E, Nunez A, Spencer Y, CliftonHadley R et al. (2008) Histological observations of bovine tuberculosis in lung and lymph node tissues from British deer. Veterinary Journal, 175, 409e412.

de Lisle GW, Havill PF (1985) Mycobacteria isolated from deer in New Zealand from 1970e1983. New Zealand Veterinary Journal, 33, $138 \mathbf{e} 140$.

Lugton IW, Wilson PR, Morris RS, Nugent G (1998) Epidemiology and pathogenesis of Mycobacterium bovis infection of red deer (Cervus elaphus) in New Zealand. New Zealand Veterinary Journal, 46, 147 e156.

Mackintosh CG, de Lisle GW, Collins DM, Griffin JF (2004) Mycobacterial diseases of deer. New Zealand Veterinary Journal, 52, $163 \mathbf{e} 174$.

Martın-Hernando MP, Hofle U, Vicente J, Ruiz-Fons F, Vidal D et al. (2007) Lesions associated with Mycobacterium tuberculosis complex infection in the European wild boar. Tuberculosis, 87, 360e367.

Naranjo V, Acevedo-Whitehouse K, Vicente J, Gortazar C, de la Fuente J (2008) Influence of methylmalonyl-CoA mutase alleles on resistance to bovine tuberculosis in the European wild boar (Sus scrofa). Animal Genetics, 39, 316e320.

Partridge T, Toolan D, Egan J, More S (2008) Control of Mycobacterium bovis infection in two sika deer herds in Ireland. Irish Veterinary Journal, 61, 27e32.

Rhyan JC, Saari DA (1995) A comparative study of the histopathologic features of bovine tuberculosis in cattle, fallow deer (Dama dama), sika deer (Cervus nippon), and red deer and elk (Cervus elaphus). Veterinary Pathology, 32, 215 e220.

Robinson RC, Phillips PH, Stevens G, Storm PA (1989) An outbreak of Mycobacterium bovis infection in fallow deer (Dama dama). Australian Veterinary Journal, 66, 195 e197.

Rohonczy EB, Balachandran AV, Dukes TW, Payeur JB, Rhyan JC et al. (1996) A comparison of gross pathology, histopathology, and mycobacterial culture for the diagnosis of tuberculosis in elk (Cervus elaphus). Canadian Journal of Veterinary Research, 60, $108 \mathbf{e} 114$.

Saenz de Buruaga M, Lucio AJ, Purroy J (1991) Reconocimiento de Sexo y Edad en Especies Cinegeticas. Diputacion Foral de Alava, Vitoria, pp. 34e40.

Stuart FA, Manser PA, McIntosh FG (1988) Tuberculosis in imported red deer (Cervus elaphus). Veterinary Record, 122, 508e511.

VerCauteren KC, Atwood TC, DeLiberto TJ, Smith HJ, Stevenson JS et al. (2008) Sentinel-based surveillance of coyotes to detect bovine tuberculosis, Michigan. Emerging Infectious Diseases, 14, 1862e 1869.

Vicente J, Hofle U, Garrido JM, Fernandez-de-Mera IG, Juste R et al. (2006) Wild boar and red deer display high prevalences of tuberculosis-like lesions in Spain. Veterinary Research, 37, 107e119.

Wahlstrom H, Englund L, Carpenter T, Emanuelson U, Engvall A et al. (1998) A reed-frost model of the spread of tuberculosis within seven Swedish extensive farmed fallow deer herds. Preventive Veterinary Medicine, 35, $181 \mathrm{e} 193$.

Wangoo A, Johnson L, Gough J, Ackbar R, Inglut S et al. (2005) Advanced granulomatous lesions in Mycobacterium bovis infected cattle are associated with increased expression of type I procollagen, gamma delta (WC1+) $\mathrm{T}$ cells and CD68(+) cells. Journal of Comparative Pathology, $133,223 \mathbf{e} 234$

Wilson P, Harrington R (1976) A case of bovine tuberculosis in fallow deer. Veterinary Record, 98, 74.

Zanella G, Duvauchelle A, Hars J, Moutou F, Boschiroli ML et al. (2008) Patterns of lesions of bovine tuberculosis in wild red deer and wild boar. Veterinary Record, 163, 43e 47.

\footnotetext{
1/. Received, February 17th, 2009

Accepted, July 8th, 2009
} 